\title{
Afferent Regulation of Inhibitory Synaptic Transmission in the Developing Auditory Midbrain
}

\author{
Carmen Vale ${ }^{1}$ and Dan H. Sanes ${ }^{1,2}$ \\ ${ }^{1}$ Center for Neural Science and 2Department of Biology, New York University, New York, New York 10003
}

To determine whether afferent innervation regulates the strength of inhibitory connections in the gerbil auditory midbrain, both cochleas were surgically removed in postnatal day 7 animals, before sound-driven activity is first observed. Inhibitory synaptic currents were measured in a brain slice preparation 1-7 $d$ after the ablations. Whole-cell and gramicidinperforated patch recordings were obtained from inferior colliculus neurons, and IPSCs were evoked by stimulation of the commissure of the inferior colliculus $(\mathrm{CIC})$ or the ipsilateral lateral lemniscus (LL) in the presence of kynurenic acid. Deafferentation led to a $24 \mathrm{mV}$ depolarizing shift in the IPSC equilibrium potential within $1 \mathrm{~d}$ of deafferentation. As a consequence, there was a large reduction of IPSC amplitude at a holding potential of $-20 \mathrm{mV}$ in neurons from bilaterally ablated animals. Furthermore, both afferent pathways displayed a 50\% reduction of the inhibitory synaptic conductance after deafferentation, indicating that driving force was not solely responsible for the decline in IPSC amplitude. When paired pulses were delivered to the LL or CIC pathway in control neurons, the evoked IPSCs exhibited facilitation. However, paired pulse facilitation was nearly eliminated after deafferentation. Thus, normal innervation affects inhibitory synaptic strength by regulating postsynaptic chloride homeostasis and presynaptic transmitter release properties.

Key words: $G A B A_{A}$ receptor; glycine receptor; inferior colliculus; inhibitory; gerbil; deafness
Spontaneous and evoked electrical activity play a critical role in the maturation of central neuronal circuits. Complete or partial sensory deprivation can produce alterations at all levels of the system, and these effects are most profound during early development. For example, the loss or complete inactivation of the cochlea leads to the cessation of protein synthesis, cell shrinkage, dendrite retraction, and cell death in the chick auditory brainstem (Parks, 1979; Deitch and Rubel, 1984; Born and Rubel, 1988). To understand how alteration of synaptic architecture and protein expression might affect synaptic processing, it is important to learn the functional properties of these connections. Because central neurons receive a rich array of excitatory, inhibitory, and modulatory afferents, it is necessary to study their response to disuse on an individual basis. The present study examines the effect of deafferentation on inhibitory afferents in the auditory midbrain.

Use-dependent alterations of inhibitory synapses have been demonstrated in the developing and adult nervous system. When organotypic cultures of the mouse cerebellum are grown in tetrodotoxin to block electrical activity, the number of inhibitory synapses is selectively reduced (Seil and Drake-Baumann, 1994). The regulation of inhibitory synaptic strength may derive, in part, from the stimulation of receptor synthesis and clustering by GABA and glycine (Poulter et al., 1997; Kirsch and Betz, 1998). Alternatively, the accumulation and release of transmitter may also be compromised by changes in the level of activity (Hendry and Jones, 1986; Wickesberg et al., 1994; Hirsch et al., 1999).

We have previously shown that denervated afferent pathways

\footnotetext{
Received July 19, 1999; revised Dec. 7, 1999; accepted Dec. 20, 1999.

This work was supported by National Institutes of Health Grant DC00540.

Correspondence should be addressed to Dan H. Sanes, Center for Neural Science, 4 Washington Place, New York University, New York, NY 10003. E-mail: sanes@cns.nyu.edu.

Copyright (C) 2000 Society for Neuroscience $\quad 0270-6474 / 00 / 201912-10 \$ 15.00 / 0$
}

undergo rapid changes in strength. For example, evoked inhibitory postsynaptic responses in the lateral superior olivary nucleus (LSO) become smaller within $24 \mathrm{hr}$ of deafferentation (Kotak and Sanes, 1996). Furthermore, this decrease is accompanied by a $8 \mathrm{mV}$ depolarization in the IPSP reversal potential, suggesting that chloride homeostasis might be affected. Inhibitory disuse also results in heterosynaptic affects. Thus, when the contralateral inhibitory input is disrupted, the unmanipulated excitatory pathway becomes stronger, apparently because of the addition of functional NMDA receptors (Kotak and Sanes, 1996). Changes in the strength of inhibitory afferents have also been suggested by in vivo studies of deafness and presbycusis (Kitzes and Semple, 1985; Milbrandt et al., 1994; Bledsoe et al., 1995; Caspary et al., 1995; McAlpine et al., 1997; Milbrandt et al., 1997).

These studies raise interesting questions about the functional status of synapses in higher regions of the CNS. Therefore, we examined the inferior colliculus where the role of synaptic inhibition in auditory processing has been most broadly studied (Park and Pollak 1993a,b, 1994; Le Beau et al., 1996; Sanes et al., 1998). The present study asked whether the disruption of all spontaneous activity generated in the cochlea before the onset of sounddriven activity commenced would influence the functional development of two different inhibitory pathways through the lateral lemniscus (LL) and the commissure of the inferior colliculus (CIC).

Parts of these results were published previously in abstract form (Vale and Sanes, 1999).

\section{MATERIALS AND METHODS}

Cochlear ablation. All protocols were reviewed and approved by the New York University Institutional Animal Care and Use Committee. Cochlear ablations were performed as described previously (Sanes et al., 1992). Gerbil (Meriones unguiculatus) pups at postnatal day 7 (P7) were anesthetized with hypothermia until respiration ceased and animals did not respond to nociceptive stimuli. A small hole was made in the cochlear 
wall, and the contents were rapidly removed with a forceps. A piece of Gelfoam was placed in the cavity, and the wound was closed. Ablations were performed bilaterally. After surgery, animals were warmed on a heating pad and returned to the litter when respiration and motor activity recovered. Bilaterally ablated animals were fed with a sterile saline solution containing $0.1 \%$ glucose at $2-3$ d after surgery. Successful ablations were confirmed before each brain slice experiment.

Brain slice preparation. Control and bilaterally ablated P8-P14 gerbils were anesthetized with chloral hydrate $(350 \mathrm{mg} / \mathrm{kg})$. After decapitation, the brain was blocked at the level of the thalamus and the caudal hindbrain. The ventral surface of the brain was affixed to an agar block (cyanoacrylate glue), and the block was secured to the stage of a vibratome (Leica, Nussloch, Germany). The tissue was cut in cold oxygenated artificial CSF (ACSF) containing (in $\mathrm{mM}$ ): $123 \mathrm{NaCl}, 4 \mathrm{KCl}, 1.2$ $\mathrm{KH}_{2} \mathrm{PO}_{4}, 1.3 \mathrm{MgSO}_{4}, 28 \mathrm{NaHCO}_{3}, 15$ glucose, $2.4 \mathrm{CaCl}_{2}$, and 0.4 L-ascorbic acid, pH 7.3 when oxygenated with $95 \% \mathrm{O}_{2} / 5 \% \mathrm{CO}_{2}$. Slices of $300 \mu \mathrm{m}$ were obtained in cold ACSF and maintained in an incubation chamber at room temperature for $2 \mathrm{hr}$. Slices containing the rostral inferior colliculus (IC) were placed in a recording chamber and superfused with oxygenated ACSF $(7 \mathrm{ml} / \mathrm{min})$ at room temperature.

Electrophysiology. Whole-cell voltage-clamp recordings (Warner Instruments PC-501A) were obtained as described previously (Kotak et al., 1998; Moore et al., 1998). Recording electrodes were fabricated from borosilicate glass microcapillaries $(1.5 \mathrm{~mm}$ outer diameter $)$, and the tip resistance was 5-10 $\mathrm{M} \Omega$. For whole-cell voltage-clamp recordings, the internal pipette solution contained (in $\mathrm{mM}$ ): 127.5 cesium gluconate, 0.6 EGTA, $10 \mathrm{HEPES}, 2 \mathrm{MgCl}_{2}, 5 \mathrm{KCl}, 2 \mathrm{ATP}, 0.3 \mathrm{GTP}$, and $5 \mathrm{QX}-314$ (Alamone, Jerusalem, Israel), $\mathrm{pH}$ 7.2. A measured liquid junction potential of $\sim 5 \mathrm{mV}$ was not corrected, because our primary objective was to compare measures between control and deafferented neurons. This error should affect both values equally. Biocytin $(\sim 0.2 \%)$ was also added to the recording solution. Extracellular stimuli ( $200 \mu \mathrm{sec}$ pulses) were delivered through paired Teflon-insulated platinum electrodes driven by isolated biphasic stimulators (Intronics Instruments). Custom personal computerbased software was used for programmed stimulus delivery, data acquisition, and analysis (Sanes, 1993). Stimulating electrodes were placed in the afferent pathways from the CIC and the LL. The maximum amplitude of evoked synaptic currents was typically obtained at membrane holding potentials $\left(E_{\text {hold }}\right)$ of -80 and $-20 \mathrm{mV}$. IPSC duration was determined from the rising latency to the time at which the signal returned to the baseline noise level. The holding potential at which IPSCs reversed ( $\left.E_{\text {IPSC }}\right)$ was also measured. At the end of each recording, slices were fixed in $4 \%$ paraformaldehyde, and a subset were processed to visualize biocytin-filled neurons using an avidin-biotin complex coupled to horseradish peroxidase (Vector Laboratories, Burlingame, CA).

Passive membrane properties were evaluated using whole-cell currentclamp recordings (Warner Instruments PC-501A) in the presence of kynurenic acid. The internal pipette solution contained (in $\mathrm{mM}$ ): 135 potassium gluconate, $2 \mathrm{MgCl}_{2}, 5 \mathrm{KCl}$, $0.6 \mathrm{EGTA}, 10 \mathrm{HEPES}, 2 \mathrm{MgCl}_{2}$, 2 ATP, and 0.3 GTP, pH 7.2. The neuron input resistance was calculated from the slope of current-voltage plots. Time constants were determined as the time to reach $67 \%$ of the plateau amplitude after $0.1 \mathrm{nA}$ hyperpolarizing current pulses.

Many recordings $(n=86)$ were performed using the perforated patch technique (Rhee et al., 1994; Kyrozis and Reichling, 1995). Gramicidin (Sigma, St. Louis, MO) was used as the membrane-perforating agent to permit the recording of IPSCs without influencing the cytoplasmic chloride concentration. Gramicidin was dissolved in dimethylsulfoxide (DMSO; $2-5 \mathrm{mg} / \mathrm{ml}$ ) and then diluted in the pipette solution to a final concentration of $2-5 \mu \mathrm{g} / \mathrm{ml}(0.2 \%$ DMSO). In our preparation, a further increase in gramicidin concentrations led to rapid perforation and membrane rupture during the recordings. Gramicidin concentrations used in this study were lower than those used in some preparations (Kazaku et al., 1999) but close to those used for recordings from immature neurons of the cortex or auditory brainstem (Owens et al., 1996; Backus et al., 1998). For perforated patch recordings, $\mathrm{KCl}$ was used in the pipette solution to preserve the function of potassium chloride cotransporters. With this solution, the measured liquid junction potential was $\sim 4 \mathrm{mV}$, and the measurements were uncorrected, because our primary objective was to compare measures between control and deafferented neurons. QX-314 was retained in the intracellular pipette solution to confirm that the membrane did not rupture. The presence of depolarization-evoked breakaway action potentials was taken as indication of the integrity of the gramicidin perforation. The progress of perforation was evaluated by monitoring the decrease in membrane resistance. After the membrane resistance had stabilized (between 5 and 40 min after obtaining the G $\Omega$ seal), data were obtained.

Ionotropic glutamate receptors were blocked by adding a broadspectrum ionotropic glutamate receptor antagonist, $5 \mathrm{~mm}$ kynurenic acid (Fluka Chemical, Ronkonkoma, NY) to the ACSF. The total IPSC was blocked by the sequential addition of $2 \mu \mathrm{M}$ strychnine (Sigma), a glycine receptor antagonist, and $10 \mu \mathrm{M}$ bicuculline methobromide (Research

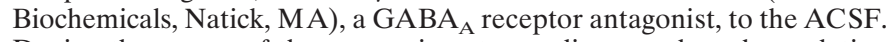
During the course of these experiments, we discovered a subpopulation of $\mathrm{GABA}_{\mathrm{A}}$ receptors that were less sensitive to bicuculline, and this antagonist was used at higher concentrations in some experiments, as indicated.

A one-way ANOVA followed by pairwise comparisons (Student's $t$ test) was used to assess whether significant differences existed between neurons from control and bilaterally ablated animals, except as noted in Results. All values are expressed as mean \pm SEM, with the number of observations in parentheses. The $E_{\text {IPSC }}$ was calculated from linear fits of the current-voltage curves plotting IPSC amplitude versus membrane holding potential. Inhibitory synaptic conductance was calculated as the slope of these same current-voltage curves.

\section{RESULTS}

Of the total number of IC neurons recorded in whole-cell voltageclamp mode from control and experimental animals $(n=49), 27$ were recovered histologically and were assigned to locations in the rostrocaudal plane and the central or lateral position. Fourteen cells were located in central positions, and the remaining stained cells were located either in lateral positions in the IC or in the border between the central and external cortex of the IC. Centrally located neurons within the IC generally exhibited the largest postsynaptic currents. All recorded IC neurons displayed a synaptic response to independent stimulation of the CIC and the LL afferent pathways. Before the addition of kynurenic acid, LL- and CIC-evoked compound PSCs were typically inward at $E_{\text {hold }}=-80$ and outward or mixed at $E_{\text {hold }}=-20$ (Fig. 1).

\section{Synaptic physiology in control neurons}

The LL-evoked PSC amplitudes are shown for control neurons in Table 1 and Figure $1 A$. At $E_{\text {hold }}=-80$, the application of kynurenic acid (KYN) reduced LL-evoked inward synaptic currents by $>60 \%$ but did not affect PSC amplitude at $E_{\text {hold }}=-20$ (Table 1). The synaptic current that remained in the presence of KYN (total IPSC) was composed of glycinergic and GABAergic components. The addition of $2 \mu \mathrm{M}$ strychnine $(\mathrm{SN})$ decreased the IPSC by $35-40 \%$, and the addition of $10 \mu \mathrm{M}$ bicuculline (BIC) led to a further reduction in amplitude (Table 1, Fig. $1 A$ ). However, a significant synaptic current $(>20 \mathrm{pA})$ remained in 7 of 17 control IC neurons, even in the presence of all three antagonists. Three of these neurons were tested with $5 \mu \mathrm{M}$ SN, but this did not decrease the remaining current. In four of these neurons, increasing $\mathrm{BIC}$ to $20-50 \mu \mathrm{M}$ led to the elimination of the remaining currents.

Given the apparent differential sensitivity of IC neurons to bicuculline, a set of dose-response experiments were performed with BIC. Figure $2 A$ shows the response of increasing BIC concentrations on the amplitude of the postsynaptic GABAergic current in one IC neuron (in the presence of KYN and SN). The inhibition produced by $10 \mu \mathrm{M}$ BIC varied from 50 to $100 \%$ among the individual IC neurons (Fig. $2 B$ ). In all cases, the remaining currents in the presence of KYN, SN, and $10 \mu \mathrm{M}$ BIC were completely abolished by increasing the concentration of BIC to $50 \mu \mathrm{M}$.

Bilateral deafferentation: passive membrane properties Bilateral cochlear ablation (BCA) did not produce a large change in the passive membrane properties of IC neurons. Membrane 


\section{A LL-evoked currents}

Control

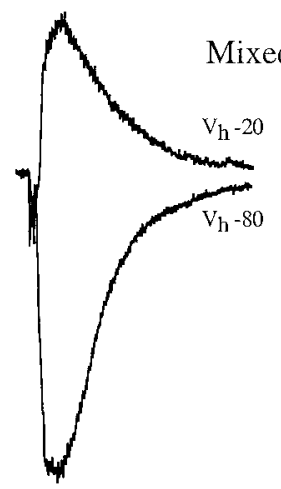

Mixed PSC (ACSF)

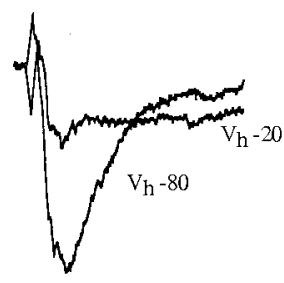

$100 \mathrm{pA} \bigsqcup_{25 \mathrm{~ms}}$

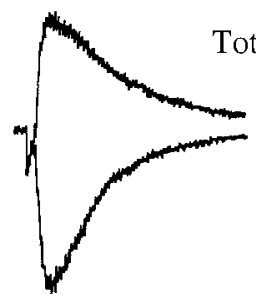

Total IPSC (KYN)
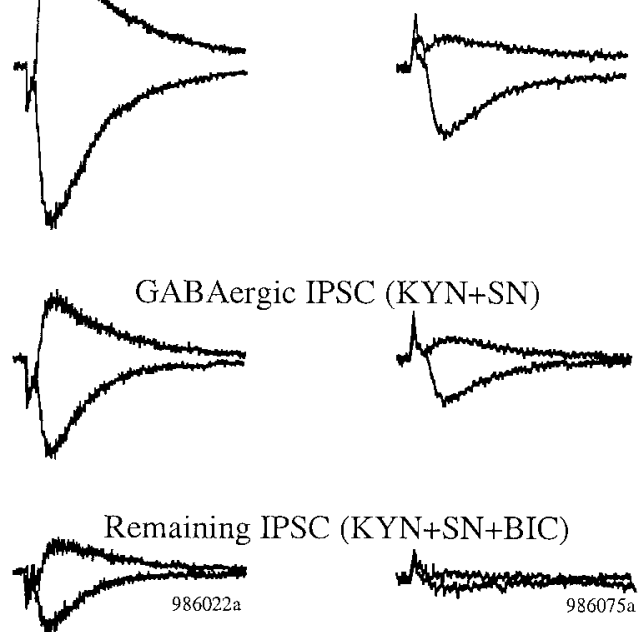

Remaining IPSC (KYN+SN+BIC)

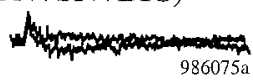

B

$\underline{\text { CIC-evoked currents }}$
Control BCA
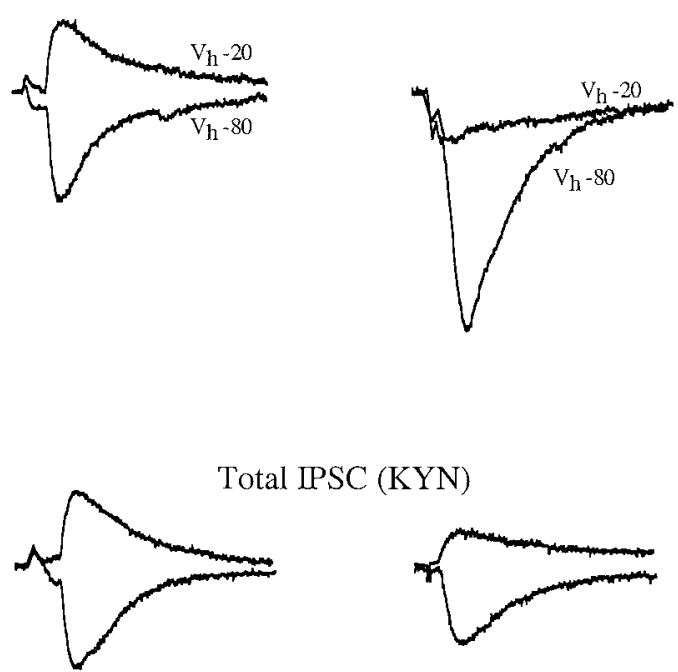

Figure 1. LL- and CIC-evoked synaptic currents from control and deafferented $(B C A)$ neurons. Recordings were performed in whole-cell voltage clamp with cesium gluconate in the internal pipette solution. $A$, LL-evoked total PSCs are inward at $-80 \mathrm{mV}$ and outward at $-20 \mathrm{mV}$ for the control neuron. In BCA neurons, the total PSC tended to be inward at both -80 and $-20 \mathrm{mV}$. In the presence of KYN the amplitude of the LL-evoked total IPSC was smaller in the BCA neuron (right) both at -20 and at $-80 \mathrm{mV}$. With the addition of SN, LL-evoked GABAergic IPSCs were also smaller in the BCA neuron (right). After the addition of BIC, a measurable LL-evoked IPSC was still present in the control neuron but was absent in the BCA neuron. $B$, CIC-evoked PSCs were inward at $-80 \mathrm{mV}$ and outward at $-20 \mathrm{mV}$ for the control neuron. In the BCA neuron, the total PSC was inward at both -80 and $-20 \mathrm{mV}$. In the presence of KYN, the amplitude of the CIC-evoked total IPSC was smaller in the BCA neuron (right) at $-20 \mathrm{mV}$ but similar to the control neuron at $-80 \mathrm{mV}$. With the addition of SN, the CIC-evoked GABAergic IPSC was smaller in the BCA neuron (right) at $-20 \mathrm{mV}$ but similar to the control neuron at $-80 \mathrm{mV}$. After the addition of BIC, a measurable CIC-evoked IPSC remained in the control neuron but was absent in the BCA neuron. The control neuron was from a P10 animal, and the BCA neuron was from a P11 animal.

input resistance was not significantly altered in BCA neurons (control, $311 \pm 28 \mathrm{M} \Omega ; n=15$; BCA, $268 \pm 45 \mathrm{M} \Omega ; n=16$ ). However, BCA caused a small, but significant, decrease in the membrane time constant from $30 \pm 2 \mathrm{msec}(n=15)$ in control to $22 \pm 2 \operatorname{msec}(n=16)$ in BCA neurons $(\mathrm{df}=29 ; t=-2.388 ; p=$ $0.02)$. A decrease in the membrane time constant suggests that synaptic responses should be faster in BCA neurons. However, LL-evoked IPSCs from control neurons actually exhibited a slightly larger rising slope compared with BCA neurons (control, $-55 \pm 9 \mathrm{pA} / \mathrm{msec} ; \mathrm{BCA},-32 \pm 5 \mathrm{pA} / \mathrm{msec} ; \mathrm{df}=43 ; t=2.112$; $p=0.04)$. Therefore, passive membrane properties of BCA neurons were not expected to influence our measures of synaptic transmission.

\section{Bilateral deafferentation: whole-cell voltage-clamp recordings}

The following experiments document the size of evoked synaptic currents under different pharmacological conditions. The goal was to isolate the inhibitory component (IPSCs) in control and BCA neurons. The IPSCs were analyzed at an $E_{\text {hold }}$ of -20 and $-80 \mathrm{mV}$ because the $E_{\text {IPSC }}$ was generally in between these two potentials. The changes that we observed were similar for LLand CIC-evoked synaptic currents. Therefore, the results are presented together in this section, and all results are summarized in Tables 1 and 2.

Whole-cell voltage-clamp recordings were obtained with cesium gluconate in the internal pipette solution. Figure 1 shows 


\begin{tabular}{|c|c|c|c|c|}
\hline & ACSF & KYN & $\mathrm{KYN}+\mathrm{SN}$ & $\mathrm{KYN}+\mathrm{SN}+\mathrm{BIC}$ \\
\hline \multicolumn{5}{|c|}{$E_{\text {hold }}=-80(\mathrm{pA})$} \\
\hline Control & $-377 \pm 46(27)$ & $-130 \pm 24(25)$ & $-85 \pm 21(18)$ & $-31 \pm 11(17)$ \\
\hline $\mathrm{BCA}$ & $-216 \pm 32(20)^{*}$ & $-51 \pm 10(20)^{* *}$ & $-39 \pm 9 \quad(15)$ & $-2 \pm 2(15)^{*}$ \\
\hline \multicolumn{5}{|c|}{$E_{\text {hold }}=-20(\mathrm{pA})$} \\
\hline Control & $+56 \pm 14(25)$ & $+62 \pm 12(23)$ & $+41 \pm 9$ & $+15 \pm 6$ \\
\hline BCA & $-10 \pm 14(22)^{* * *}$ & $+13 \pm 5 \quad(20)^{* * *}$ & $+11 \pm 8$ & $0 \pm 0 \quad(15)^{*}$ \\
\hline
\end{tabular}

Values are mean \pm SEM $(n)$. ACSF, No antagonists; KYN, 5 mM kynurenic acid; SN, $2 \mu \mathrm{M}$ strychnine; BIC, $10 \mu \mathrm{M}$ bicuculline.

${ }^{*} p<0.05 ;{ }^{* *} p<0.01 ;{ }^{* * *} p<0.005$ versus control neurons under the same conditions (ANOVA followed by $t$ test).

examples of afferent-evoked synaptic currents in control and BCA neurons under each pharmacological condition. Although there was a significant decrease in the maximum amplitude of the LL-evoked mixed PSCs (Table 1, Fig. $1 A$ ), we do not believe that these effects can be interpreted easily. Therefore, our analyses focused on pharmacologically isolated synaptic inhibition.

The amplitudes of LL-evoked total IPSCs were significantly decreased, both at $E_{\text {hold }}=-20$ and $-80 \mathrm{mV}$ (Fig. 1A, Table 1). The maximum amplitude of LL-evoked IPSCs was $\sim 70 \%$ smaller at $-80 \mathrm{mV}(\mathrm{df}=43 ; t=2.76 ; p=0.008)$ and $\sim 80 \%$ smaller at $-20 \mathrm{mV}$ ( df $=41 ; t=-3.63 ; p=0.0008)$. Furthermore, IPSC duration was also decreased significantly after ablation ( $\mathrm{df}=43 ; t=-3.81 ; p=0.0004)$. For example, at a holding potential of $-80 \mathrm{mV}$, control IPSCs had a maximum duration of $125 \pm 12 \mathrm{msec}(n=25)$, and this declined to $61 \pm 11 \mathrm{msec}(n=$ $20)$ in BCA neurons.

The amplitude of CIC-evoked postsynaptic currents in control and BCA neurons under each pharmacological condition is shown in Figure $1 B$ and Table 2. Interestingly, BCA neurons only displayed smaller IPSCs at $E_{\text {hold }}=-20 \mathrm{mV}(\mathrm{df}=44 ; t=-2.82$; $p=0.007$ ). At this holding potential, the maximum CIC-evoked total IPSCs were $\sim 80 \%$ smaller than those of control neurons (Fig. 1B, Table 2). Although the mean total IPSC amplitude was $40 \%$ below controls at $E_{\text {hold }}=-80$, this value did not reach significance.

The dissimilar findings at each holding potential could be explained if $E_{\text {IPSC }}$ shifted toward $-20 \mathrm{mV}$ in BCA neurons. That is, the reduced IPSC amplitude at a holding potential of $-20 \mathrm{mV}$ may be attributable to reduced activity of GABA or glycine receptors, decreased presynaptic transmitter release, and a decreased driving force. In contrast, the IPSC amplitude recorded at a holding potential of $-80 \mathrm{mV}$ was not reduced, because an increase in chloride driving force could compensate for decreased receptor function or transmitter release.

In fact, BCA neurons exhibited a significant depolarizing shift in the total IPSC reversal potential $(\mathrm{df}=41 ; t=2.9 ; p=0.005)$. The $E_{\text {IPSC }}$ of control neurons was $-40 \pm 3(n=23)$ versus $-26 \pm$ $4(n=20) \mathrm{mV}$ in BCA neurons. A similar finding was observed for LL-evoked IPSCs (data not shown). Figure 3 shows examples of $E_{\text {I PSC }}$ measured in one control and one BCA neuron. Because the driving force $\left(E_{\text {hold }}-E_{\text {IPSC }}\right)$ influences IPSC amplitude, the inhibitory conductance was calculated from the slope of the IPSC current-voltage curves. For CIC-evoked currents, there was a significant decrease in the conductance of the total IPSC ( $\mathrm{df}=$ $36 ; t=-2.66 ; p=0.011$ ) in BCA neurons (Fig. 4). The conductance for LL-evoked total IPSC was also significatively decreased in ablated animals ( $\mathrm{df}=36 ; t=-3.32 ; p=0.002$ ).

To determine whether the changes in evoked-IPSCs were attributable to changes in GABAergic afferents, neurons were
A

GABAergic IPSCs (KYN+SN)

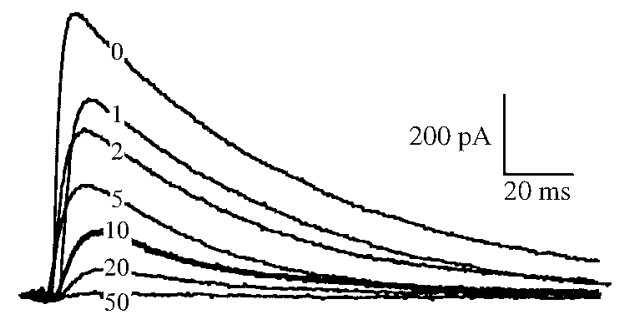

$\mathrm{B}$

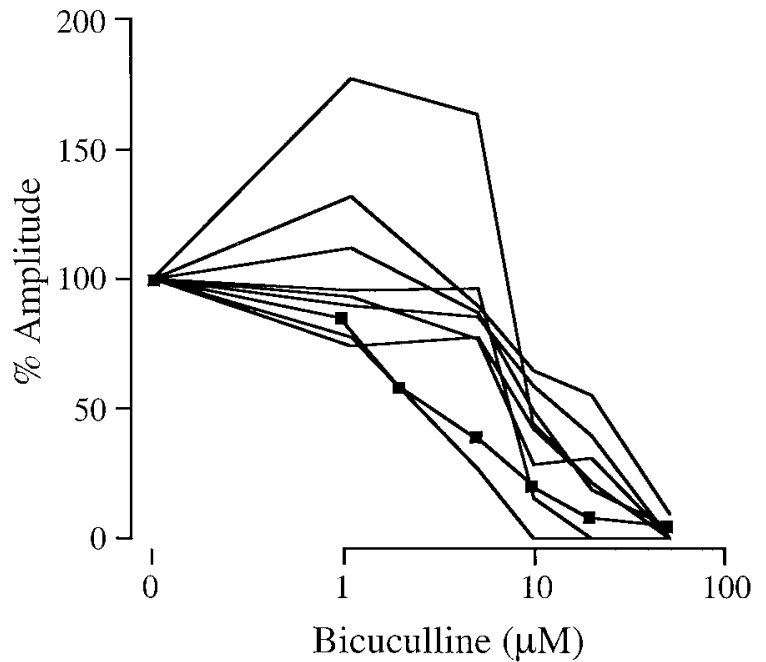

Figure 2. Sensitivity of LL-evoked GABAergic IPSCs to bicuculline in control neurons. $A$, LL-evoked GABAergic IPSCs were obtained in the presence of $5 \mathrm{~mm} \mathrm{KYN}$ and $2 \mu \mathrm{M} \mathrm{SN}$ at a holding potential of $0 \mathrm{mV}$. The BIC concentration is indicated on each trace. In this P14 neuron, there was a remaining IPSC at $20 \mu \mathrm{M}$ BIC, but $50 \mu \mathrm{M}$ eliminated the response. $B$, Bicuculline dose-response curves are shown for nine IC neurons. The LL-evoked response was expressed as a percentage of GABAergic IPSC recorded in the presence of KYN and SN only. The traces in $A$ are represented by squares. The IPSC reduction produced by $10 \mu \mathrm{M}$ BIC varied among the different neurons from 40 to $100 \%$. In all neurons, the remaining IPSC was completely eliminated in the presence of $50 \mu \mathrm{M}$ BIC.

bathed in $5 \mathrm{~mm}$ KYN plus $2 \mu \mathrm{M}$ SN. Table 1 shows that LLevoked GABAergic IPSCs were smaller in BCA neurons compared with controls. Table 2 shows that CIC-evoked IPSCs were smaller at a holding potential of -20 but not $-80 \mathrm{mV}$. Again, this 


\begin{tabular}{|c|c|c|c|c|}
\hline & $\mathrm{ACSF}$ & KYN & $\mathrm{KYN}+\mathrm{SN}$ & $\mathrm{KYN}+\mathrm{SN}+\mathrm{BIC}$ \\
\hline \multicolumn{5}{|c|}{$E_{\text {hold }}=-80(\mathrm{pA})$} \\
\hline Control & $-264 \pm 40(27)$ & $-102 \pm 21(24)$ & $-59 \pm 14(19)$ & $-15 \pm 4(17)$ \\
\hline BCA & $-180 \pm 29(22)$ & $-63 \pm 12(22)$ & $-53 \pm 16(16)$ & $-5 \pm 2(16)^{*}$ \\
\hline \multicolumn{5}{|c|}{$E_{\text {hold }}=-20(\mathrm{pA})$} \\
\hline Control & $+54 \pm 17(26)$ & $+61 \pm 16(24)$ & $+39 \pm 9$ & $+10 \pm 2(18)$ \\
\hline BCA & $-4 \pm 15(23)^{*}$ & $+11 \pm 5(22)^{* *}$ & $+15 \pm 5(16)^{*}$ & $+1 \pm 1(16)^{* *}$ \\
\hline
\end{tabular}

Values are mean \pm SEM $(n)$. ACSF, No antagonists; KYN, 5 mM kynurenic acid; SN, $2 \mu \mathrm{M}$ strychnine; BIC, $10 \mu \mathrm{m}$ bicuculline.

${ }^{*} p<0.05 ;{ }^{* *} p<0.01$ versus control neurons under the same conditions (ANOVA followed by $t$ test).

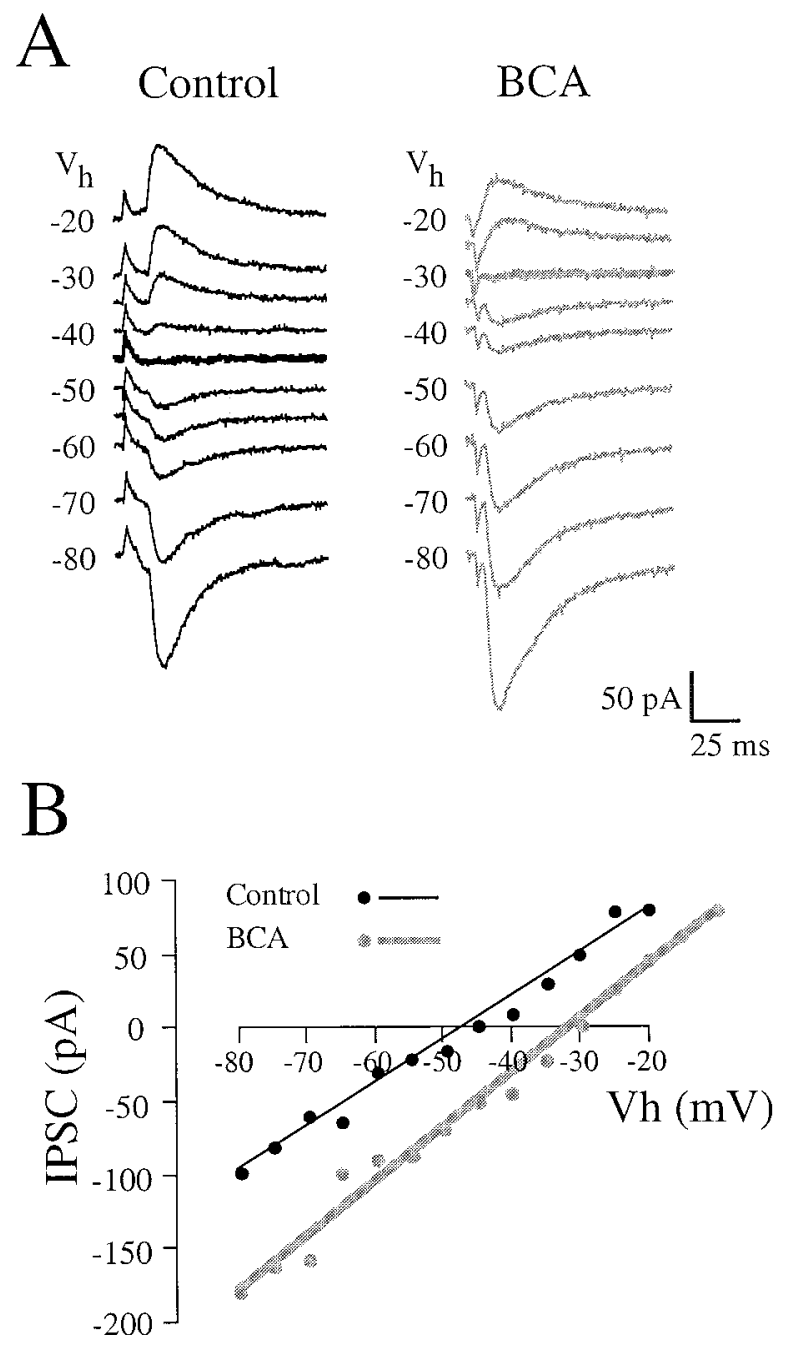

Figure 3. Effect of deafferentation on IPSC reversal potential assessed with whole-cell voltage-clamp recordings using cesium gluconate in the internal pipette solution. $A$, CIC-evoked IPSCs are shown for a P10 control neuron (left) and a P11 BCA neuron (right). B, The currentvoltage relationship for inhibitory currents shown in $A$. The plot for the BCA neuron was unusually steep even though BCA conductance was smaller on average (see Results for details). The $E_{\mathrm{IPSC}}$ was approximately $-45 \mathrm{mV}$ in the control neuron (black line) and $-30 \mathrm{mV}$ in the BCA neuron ( gray line).

was probably because of the $15 \mathrm{mV}$ depolarization of the GABAergic $E_{\text {IPSC }}$ (control, $-44 \pm 3 \mathrm{mV} ; n=18$; BCA, $-29 \pm$ $6 \mathrm{mV} ; n=14 ; \mathrm{df}=30 ; t=2.383 ; p=0.0237)$. As shown in Figure 4 , the calculated conductance for CIC-evoked GABAergic IPSCs

\section{LL-evoked IPSCs}
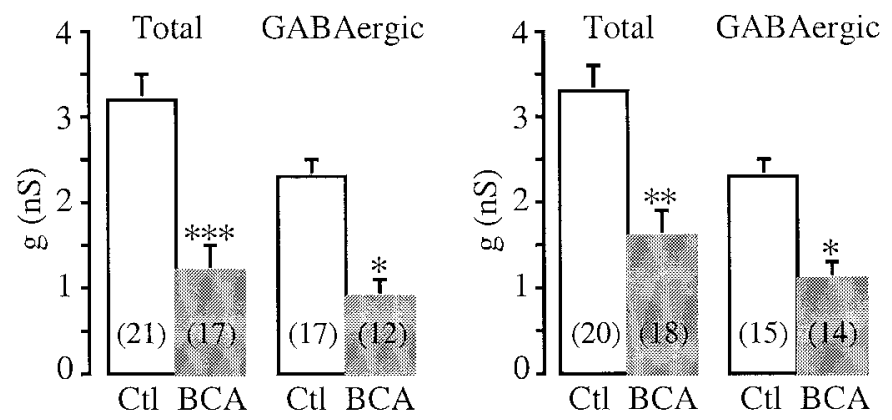

Figure 4. Conductance of LL- and CIC-evoked total and GABAergic IPSCs in control (gray bars) and BCA (open bars) neurons. Data are from whole-cell voltage-clamp recordings. Total inhibitory currents were obtained in the presence of KYN, and GABAergic synaptic currents were obtained in the presence of KYN and SN. Values are means $\pm \operatorname{SEM}(n)$. ${ }^{*} p<0.05$; ${ }^{*} p<0.01 ; * * * p<0.005$ versus control neurons under the same condition.

was $\sim 50 \%$ smaller in BCA neurons $(\mathrm{df}=27 ; t=-2.40 ; p=$ 0.023). A similar observation was made for LL-evoked GABAergic IPSCs (Fig. 4).

In control IC neurons, a significant component of the IPSC remained in the presence of all three antagonists ( $5 \mathrm{~mm} \mathrm{KYN}, 2$ $\mu \mathrm{M} \mathrm{SN}$, and $10 \mu \mathrm{M} \mathrm{BIC).} \mathrm{This} \mathrm{was} \mathrm{found} \mathrm{for} \mathrm{both} \mathrm{LL-} \mathrm{and}$ CIC-evoked IPSCs (Tables 1, 2). However, this remaining current was absent in BCA neurons at all holding potentials. Therefore, the GABAergic component that was less sensitive to BIC in control neurons (Fig. 2) was apparently absent after deafferentation.

\section{Gramicidin-perforated patch recordings}

Because our initial results with whole-cell recordings showed that the IPSC equilibrium potential was regulated by ablation, we repeated the experiments using gramicidin-perforated patch recordings in which chloride ions do not pass through the perforation. Furthermore, we used normal potassium in the pipette so as not to perturb potassium chloride cotransporter mechanisms (Kazaku et al., 1999). In perforated patch recordings, the resting membrane potential of control and BCA neurons was $-55 \pm 1$ $\mathrm{mV}(n=45)$ and $-58 \pm 1 \mathrm{mV}(n=33)$, respectively.

Figure $5 A$ shows LL-evoked IPSCs obtained at a series of holding potentials for individual control and BCA neurons. The current-voltage relationship was linear in both cases (Fig. 5B). As shown in Figure $6 A$, the $E_{\text {IPSC }}$ measured in the presence of KYN was depolarized by $24 \mathrm{mV}$ after deafferentation (control, $-74 \pm$ $2 \mathrm{mV} ; n=45 ; \mathrm{BCA},-50 \pm 2 \mathrm{mV} ; n=33 ; \mathrm{df}=76 ; t=8.537 ; p<$ $0.0001)$. The intracellular $\mathrm{Cl}^{-}$concentration $\left(\left[\mathrm{Cl}^{-}\right]_{\mathrm{i}}\right)$ was calcu- 


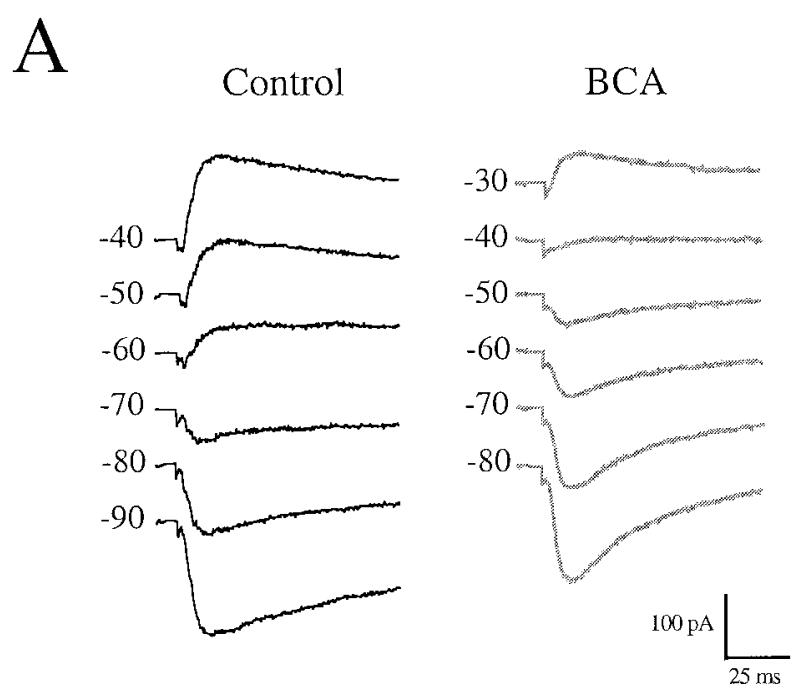

B

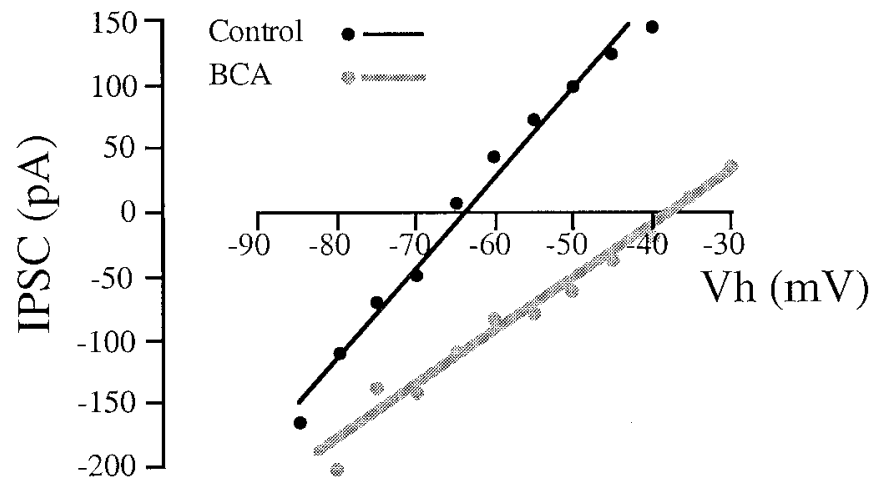

Figure 5. Effect of deafferentation on IPSC reversal potential assessed with gramicidin-perforated patch recordings and potassium chloride in the internal pipette solution. $A$, LL-evoked IPSCs are shown for a P10 control neuron (left) and a P8 BCA neuron (right). B, Current-voltage relationship for inhibitory currents shown in $A$. The $E_{\mathrm{IPSC}}$ was approximately $-65 \mathrm{mV}$ in the control neuron (black line) and $-40 \mathrm{mV}$ in the BCA neuron ( gray line).

lated by the Nernst equation, assuming: $E_{\mathrm{Cl}^{-}}=E_{\mathrm{IPSP}}=\mathrm{RT} /$ $F \ln \left(\left[\mathrm{Cl}^{-}\right]_{\mathrm{o}} /\left[\mathrm{Cl}^{-}\right]_{\mathrm{i}}\right)$. Given an extracellular free $\mathrm{Cl}^{-}$concentration $\left(\left[\mathrm{Cl}^{-}\right]_{\mathrm{o}}\right)$ of $133.8 \mathrm{~mm}$, and $\mathrm{T}=293 \mathrm{~K}\left(20^{\circ} \mathrm{C}\right)$, the estimated $\left[\mathrm{Cl}^{-}\right]_{\mathrm{i}}$ was elevated from $8 \pm 1 \mathrm{mM}(n=45)$ in control neurons to $22 \pm 3 \mathrm{~mm}(n=33)$ in BCA neurons. This calculation assumes that the ligand-coupled channels are exclusively permeable to $\mathrm{Cl}^{-}$. As shown in Figure $6 B$, the effect of deafferentation on $E_{\text {IPSC }}$ was rapid. The regression lines through the plot indicate that the control and experimental groups diverged within $1 \mathrm{~d}$ of the manipulation. Multiple ANOVA of these data indicated a significant effect of both age $(F=5.12 ; p=0.026)$ and experimental condition $(F=73.96 ; p<0.0001)$. Also shown in Figure $6 B$ are the results of recordings from control $\mathrm{P} 7$ neurons, the age of the bilateral ablations, which showed that $E_{\text {IPSC }}$ was $-55 \pm 5$ $\mathrm{mV}(n=8)$.

Because the effect of BCA was very rapid (Fig. 6B), an additional set of control experiments were performed to determine whether the short period of surgical anoxia could account for the findings. P7 animals were anesthetized with hypothermia until respiration stopped, but no surgery was performed. Recordings were then made at $\mathrm{P} 10-\mathrm{P} 11$ to determine the possible influence of anoxia. The $E_{\text {IPSC }}$ for neurons from anesthetized animals was $-68 \pm 3 \mathrm{mV}(n=6)$, and this value was not significantly different from neurons from nonanesthetized age-matched controls $(\mathrm{df}=$ 26; $t=1.769 ; p>0.05)$.

\section{Paired pulse facilitation in control and deafferented neurons}

The presynaptic release characteristics were evaluated by delivering paired stimulus pulses and measuring the relative amplitude of the second IPSC. Two pulses of equal strength were delivered at interpulse intervals of 200, 100, 50, and $33 \mathrm{msec}$. This analysis was performed with stimuli that elicited a minimum IPSC amplitude (presumed to reflect the evoked response of one or a few inhibitory terminals). As shown in Figure $7 A$, control neurons showed an increase in the amplitude of the second LL-evoked IPSC compared with the first at all interpulse intervals tested, and this facilitation was small or absent in BCA neurons. Figure $7 B$ shows the mean values for each pulse interval. Significant differences between control and BCA neurons were observed at stimulus intervals of $10(\mathrm{df}=29 ; t=-2.11 ; p<0.043), 20(\mathrm{df}=29$; $t=-3.81 ; p<0.001)$, and $30 \mathrm{~Hz}(\mathrm{df}=27 ; t=-2.93 ; p=0.007)$. Results were similar for paired pulses delivered to the CIC pathway (data not shown).

\section{DISCUSSION}

The major finding of this study was that deafferentation influenced the development of inhibitory synapses in IC neurons via a postsynaptic alteration of the chloride equilibrium potential and a change in presynaptic release mechanisms. The bilateral cochlea ablations were performed at P7, $\sim 4 \mathrm{~d}$ before the onset of sounddriven activity, and the synaptic effects were observed within 24 hr. Cell death can be detected in the gerbil cochlear nucleus at $2 \mathrm{~d}$ after ablation (Hashisaki and Rubel, 1989), although the process is not yet complete. Therefore, we suggest that changes in synaptic transmission were elicited by both the loss of spontaneous synaptic activity and the physical loss of afferents. In fact, spontaneous discharges have been recorded in the gerbil IC from P9 to P13 (Kotak and Sanes, 1995). Moreover, spontaneous activity in the IC is much lower in acutely ablated animals (Bock and Webster, 1974; Shepherd et al., 1999). The effects were similar, but not identical, for inhibitory afferents of the LL and CIC pathways. Although this could be attributable to the differential loss of afferents in the two pathways that is secondary to denervation, there is currently no information on this point. Deafferentation did not alter resting membrane potential or input resistance. There was a small, but significant, decrease in the membrane time constant, suggesting that BCA neurons may have atrophied, resulting in a smaller membrane capacitance. Because the slope of LL-evoked IPSC was actually faster in BCA neurons (see Results), the passive membrane properties did not apparently affect our measures of synaptic transmission.

\section{Inhibitory synaptic currents in control IC neurons}

Both CIC and the LL provide strong inhibitory and excitatory input to gerbil IC neurons, and such mixed input can be dissected pharmacologically in a brain slice preparation (Smith, 1992; Wagner, 1996; Lo et al., 1998; Moore et al., 1998). Because total PSCs are a result of complex interactions between excitatory and inhibitory components (Moore et al., 1998), we chose not to calculate the "excitatory" component by substracting total IPSCs from the compound PSCs. Therefore, the present study leaves open the question of whether there is BCA-induced modification of LL- 

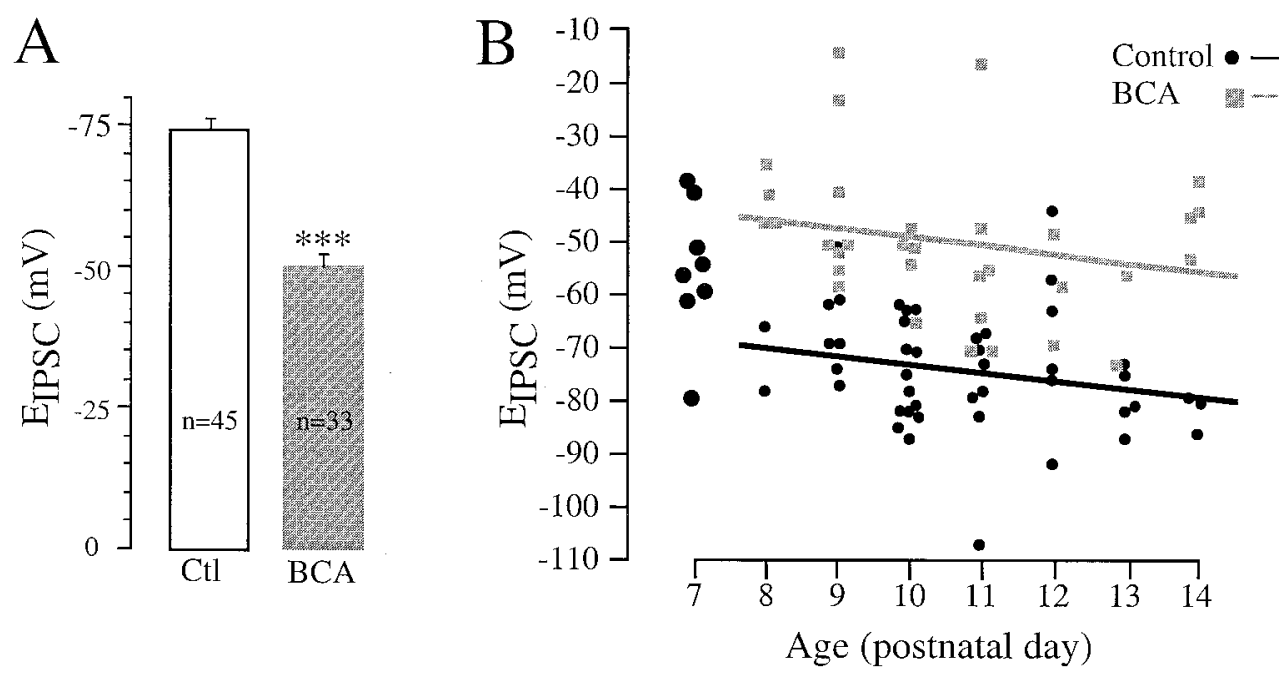

Figure 6. IPSC reversal potential in gramicidin-perforated patch recordings with $\mathrm{KCl}$ in the internal pipette solution. $A$, BCA caused a $24 \mathrm{mV}$ depolarization in the mean $E_{\mathrm{IPSC}}\left({ }^{* * *} p<0.0001 \mathrm{vs}\right.$ control). $B$, The distribution of $E_{\mathrm{IPSC}}$ is plotted for neurons from control (black circles) and bilaterally ablated (gray squares) animals, along with regression lines. The effect of deafferentation on $E_{\text {IPSC }}$ was apparent within $1 \mathrm{~d}$ of the surgical manipulation at P7 and persisted during the age range studied (up to P14). The $E_{\text {IPSC }}$ of control neurons at P7 is shown at the left (see Results for statistics).

and CIC-evoked excitatory synaptic currents. Furthermore, although much is known about the anatomy of ascending inhibitory projections to the IC, the present findings do not identify how each afferent source is affected by the manipulation (Adams, 1979; Nordeen et al., 1983; Coleman and Clerici, 1987; Shneiderman et al., 1988, 1993; Saint Marie and Baker, 1990; Saldaña and Merchan, 1992; Malmierca et al., 1995; Winer et al., 1995; González-Hernández et al., 1996; Merchan et al., 1997; Oliver et al., 1997; Saint Marie et al., 1997).

All neurons displayed LL- and CIC-evoked IPSCs (Fig. 1; Tables 1, 2), similar to our published results (Moore et al., 1998), with the exception that the recorded currents were somewhat larger in the present study. This may be attributed to the location of recording. In this study, recording sites were restricted to the most central region of the IC at a rostrocaudal level that included the largest number of lemniscal fibers entering the ventral IC. Our experience is that neurons in this location tend to have the largest evoked inhibitory currents. Both LL- and CIC-evoked IPSCs had comparable GABAergic and glycinergic components. Moore et al. (1998) showed that the LL pathway provided GABAergic and glycinergic input to IC neurons, as expected from the diverse innervation that IC neurons receive from auditory brainstem nuclei (Saint Marie and Baker, 1990; Shneiderman et al., 1993; González-Hernández et al., 1996; Saint Marie et al., 1997). It is possible that the SN-sensitive component of CICevoked IPSCs was an artifact, because immunocytochemical studies indicate that inhibitory CIC projections are GABAergic (González-Hernández et al., 1996), and glycinergic neurons are absent in adult IC (Winer et al., 1995). The close proximity of the CIC stimulating electrode to the border of IC could have directly activated glycinergic terminals within the IC. However, direct stimulation of terminals attributable to current spread would have produced a negligible latency between stimulus artifact and IPSC onset, and this was not observed (Fig. 1B). A more plausible explanation is the coexistence of both GABA- and glycinemediated inhibition in immature CIC afferents. For example, inhibitory afferents in the developing LSO co-release GABA and glycine, but the GABAergic component declines with age (Kotak et al., 1998).
Control neurons also displayed a differential sensitivity to bicuculline (Fig. 2). Similar results have been reported previously in developing tissue (Liu et al., 1998). This observation suggests that $\mathrm{GABA}_{\mathrm{A}}$ receptor subunit expression in the developing IC may produce heteromeric receptors with different pharmacological characteristics (Laurie et al., 1992; Fritschy et al., 1994).

\section{Inhibitory synaptic strength decreases after deafferentation}

Bilateral cochlear ablation at P7 caused a significant decrease in the amplitude of evoked inhibitory synaptic currents in the IC (Fig. 1; Tables 1, 2). This effect was more pronounced in the LL pathway compared with the CIC pathway, possibly because of a decrease in the number of presynaptic afferents from lower brainstem nuclei. A decrease in the number of inhibitory LL afferents would be expected, because partial or complete cochlear dysfunction during early postnatal development can produce rapid cell death in the cochlear nucleus (Parks, 1979; Hashisaki and Rubel, 1989). It is not known whether there is compensatory sprouting after bilateral ablation, as occurs in unilaterally ablated animals (Moore and Kitzes, 1985; Kitzes et al., 1995; Russell and Moore, 1995).

Whether or not afferents were lost after deafferentation, this study demonstrated that the physiology of remaining inhibitory afferents was altered significantly. In particular, the reversal potential of evoked IPSCs was depolarized. Our initial whole-cell recordings showed a $14 \mathrm{mV}$ depolarization for total IPSCs and for the pure GABAergic IPSCs (Fig. 3). However, even control neurons displayed IPSC reversal potentials that were positive to that predicted by the intracellular and extracellular $\mathrm{Cl}^{-}$concentrations. One factor that may lead to a depolarized $E_{\text {IPSC }}$ is the presence of cesium in the recording pipette, which may cause a reversal of the potassium chloride cotransporter (Kazaku et al., 1999). Therefore, an extensive set of recordings was made in control and ablated animals using gramicidin-perforated patch recordings (Rhee et al., 1994; Kyrozis and Reichling, 1995; Owens et al., 1996) with potassium chloride in the pipette solution.

In perforated patch recordings, the mean $E_{\mathrm{IPSC}}$ from BCA 
A

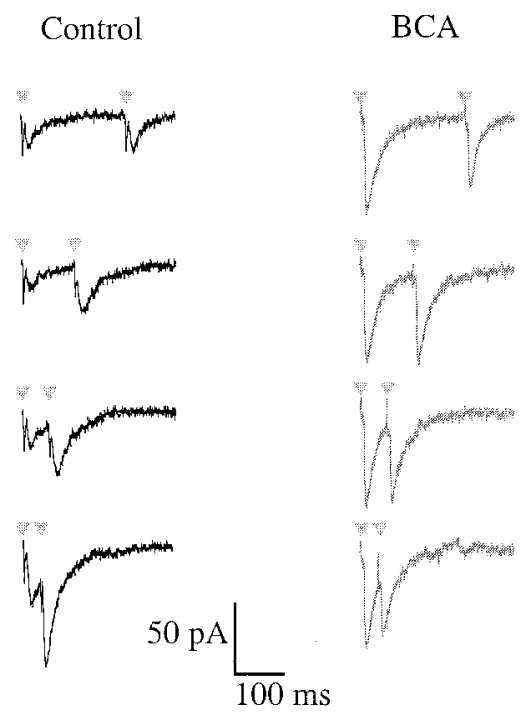

B

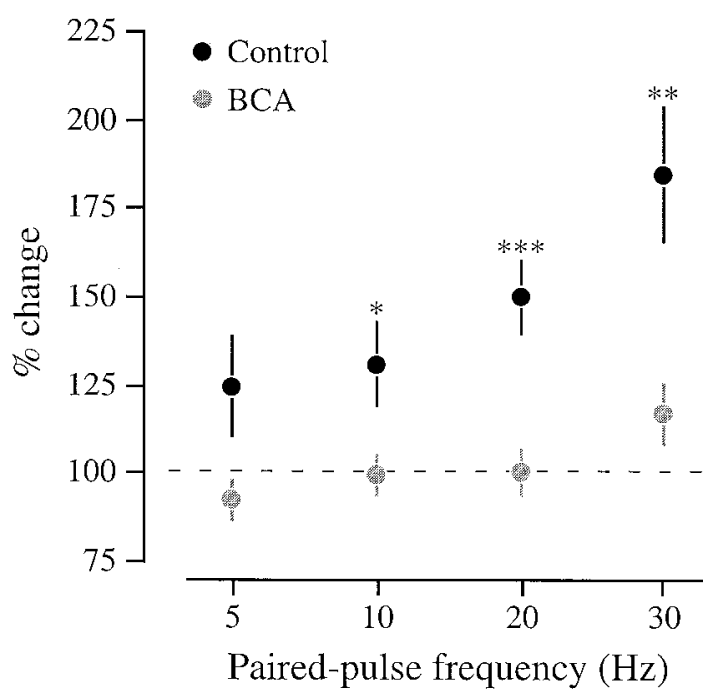

Figure 7. Analysis of paired pulse facilitation. A, Stimuli that evoked the minimum IPSC amplitude were delivered to the LL pathway at frequencies of $5,10,20$, and $30 \mathrm{~Hz}$ in a control (left) and a BCA (right) neuron. The amplitude of the second IPSC was larger at all the stimulus intervals for the control neuron (left) but was unchanged in the BCA neuron (right). The holding potential was $-80 \mathrm{mV}$ (thus, synaptic currents are somewhat smaller for the control neuron, because $E_{\text {IPSC }}$ was $-45 \mathrm{mV}$, whereas $E_{\text {IPSC }}$ was $-10 \mathrm{mV}$ for the BCA neuron). $B$, Summary of the effect of paired pulse stimulation in neurons from control (black circles) and BCA (gray circles) animals. Data were obtained after electrical stimulation of the LL pathway in the presence of $5 \mathrm{~mm}$ KYN. Data from whole-cell and gramicidin-perforated recordings were pooled; $n=14$ for BCA and 17 for control. ${ }^{*} p<0.05 ;{ }^{* * *} p<0.0001$, ANOVA followed by $t$ test.

neurons was depolarized by $24 \mathrm{mV}$. Furthermore, this effect was present within $1 \mathrm{~d}$ of bilateral ablation (Figs. 5, 6). A similar observation was made previously in the LSO, although the data were obtained with whole-cell recordings in current clamp (Kotak and Sanes, 1996). A depolarization of $E_{\text {I PSC }}$ would be expected to alter the IPSC driving force, and this would affect the IPSC amplitude recorded at different holding potentials. Thus, our failure to see significant changes on the CIC-evoked total and GABAergic IPSCs and LL-evoked GABAergic IPSCs at -80 $\mathrm{mV}$ is attributable to the fact that the depolarization of $E_{\text {IPSC }}$ increased the driving force when BCA neurons were held at -80 $\mathrm{mV}$, enhancing the evoked IPSC amplitude.

The mechanisms responsible for $E_{\text {IPSC }}$ depolarization are not yet understood; a growing body of literature indicates that the complement of chloride transporter proteins may underlie the depolarizing GABA- and glycine-evoked responses in immature neurons (Payne et al., 1996; Plotkin et al., 1997; Backus et al., 1998; Kazaku et al., 1999; Rivera et al., 1999; Williams et al., 1999). Furthermore, anoxia has been shown to depolarize the reversal potential of GABAergic IPSCs in the hippocampus (Katchman et al., 1994). Thus, we would speculate that the intracellular chloride accumulation induced by deafferentation is caused by an alteration of chloride extrusion mechanisms, such as the $\mathrm{K}^{+} / \mathrm{Cl}^{-}$cotransporter. Alternatively, the $\mathrm{Na}^{+} / \mathrm{K}^{+} / \mathrm{Cl}^{-}$ (NKCC) cotransporter, which pumps chloride into the postsynaptic cell, may be overactive. It has been found that NMDA receptor activation can stimulate an NKCC cotransporter (Sun and Murali, 1998). Whether BCA causes GABAergic and glycinergic transmission to become excitatory (e.g., to evoke action potentials) remains to be determined.

There was also a large reduction of inhibitory strength that was apparently independent of driving force. The conductance of evoked IPSCs was reduced by $\sim 50 \%$, and this was found for both the LL and CIC afferents (Fig. 4). This could have occurred as a result of loss of inhibitory afferents, reduction in the amount of GABA or glycine release, reduction of postsynaptic GABA or glycine receptors, or an alteration in the functional status of these receptors. In fact, we observed that deafferentation resulted in the apparent loss of a class of $\mathrm{GABA}_{\mathrm{A}}$ receptors that are less sensitive to BIC. In control neurons, there was often an evoked IPSC that remained in the presence of KYN, SN, and $10 \mu \mathrm{M}$ BIC. However, this remaining IPSC was not observed in BCA neurons (Tables 1, 2). This may indicate an alteration in the expression of $\mathrm{GABA}_{\mathrm{A}}$ receptor subunits, as shown in presbycusis (Milbrandt et al., 1997).

We also found that the inhibitory transmission is disrupted at presynaptic terminals after deafferentation. A paired stimulus protocol was used to evaluate the function of inhibitory terminals in control and BCA neurons (Fig. 7). Control neurons displayed an increase in the synaptic response to the second stimulus pulse at rates of 10,20 , and $30 \mathrm{~Hz}$, and this potentiation was virtually absent in BCA neurons. This observation indicates that neurotransmitter production and/or release from the presynaptic terminal is disrupted by deafferentation. A decrease in GABA release in the inferior colliculus has been reported after BCA (Bledsoe et al., 1995) and in hippocampal neurons from animals treated with kainate or pilocarpine (Hirsch et al., 1999). There is also a decrease of GABA and glycine release in several nuclei with projections to IC after partial deafferentation (Suneja et al., 1998a).

Compensatory sprouting of afferent projections after the removal of one cochlea leads to novel projections in the gerbil superior olive and inferior colliculus (Moore and Kitzes, 1985; Kitzes et al., 1995; Russell and Moore, 1995). These changes extend to a molecular level. Sensory deprivation results in alterations of transmitter release (Bledsoe et al., 1995; Potashner et al., 1997; Suneja et al., 1998a) and changes in the distribution of excitatory and inhibitory receptors (Suneja et al., 1997, 1998b; Koch and Sanes, 1998). In vivo electrophysiological studies con- 
firm that these structural alterations produce novel sound-evoked coding properties (Kitzes and Semple, 1985; Bledsoe et al., 1995). The present results indicate that normal innervation, before sound-driven activity, regulates inhibitory transmission in IC neurons. Short-term deafferentation led to a decrease in LL- and CIC-evoked IPSC amplitude, partially because of a postsynaptic alteration in chloride equilibrium potential. In addition, deafferentation caused a decrease in the functionality of single inhibitory synaptic terminals. Therefore, alterations in auditory processing after deafness may be caused by physiological changes of inhibitory synaptic transmission.

\section{REFERENCES}

Adams JC (1979) Ascending projections to the inferior colliculus. J Comp Neurol 183:519-538.

Backus KH, Deitmer JW, Friauf E (1998) Glycine-activated currents are changed by coincident membrane depolarization in developing rat auditory brainstem neurones. J Physiol (Lond) 507:783-794.

Bledsoe Jr SC, Nagase S, Miller JM, Altschuler RA (1995) Deafnessinduced plasticity in the mature central auditory system. NeuroReport $7: 225-229$

Bock GR, Webster WR (1974) Spontaneous activity of single units in the inferior colliculus of anesthetized and unanesthetized cats. Brain Res 76:150-154.

Born DE, Rubel EW (1988) Afferent influences on brain stem auditory nuclei of the chicken: presynaptic action potentials regulate protein synthesis in nucleus magnocellularis neurons. J Neurosci 8:901-919.

Caspary DM, Milbrandt JC, Helfert RH (1995) Central auditory aging: GABA changes in the inferior colliculus. Exp Gerontol 30:349-360.

Coleman JR, Clerici WJ (1987) Sources of projections to subdivisions of the inferior colliculus in the rat. J Comp Neurol 262:215-226.

Deitch JS, Rubel EW (1984) Afferent influences on brain stem auditory nuclei of the chicken: time course and specificity of dendritic atrophy following deafferentation. J Comp Neurol 229:66-79.

Fritschy JM, Paysan J, Enna A, Mohler H (1994) Switch in the expression of rat $\mathrm{GABA}_{\mathrm{A}}$-receptor subtypes during postnatal development: an inmunohistochemical study. J Neurosci 14:5302-5324.

González-Hernández T, Mantolan-Sarmiento B, González-González B, Perez-Gonzalez H (1996) Sources of GABAergic input to the inferior colliculus of the rat. J Comp Neurol 372:309-326.

Hashisaki GT, Rubel EW (1989) Effects of unilateral cochlea removal on anteroventral cochlear nucleus neurons in developing gerbils. J Comp Neurol 283:465-473.

Hendry SHC, Jones EG (1986) Reduction in number of immunostained GABAergic neurones in deprived-eye dominance columns of monkey area 17. Nature 320:750-753.

Hirsch JC, Agassandian C, Merch $\beta$ n-P $\theta$ rez A, Ben-Ari Y, DeFelipe J, Esclapez M, Bernard C (1999) Deficit of quantal release in GABA in experimental models of temporal lobe epilepsy. Nat Neurosci 2:499-500.

Katchman AN, Vicini S, Hershkowitz N (1994) Mechanism of early anoxia-induced suppression of the $\mathrm{GABA}_{\mathrm{A}}$-mediated inhibitory postsynaptic current. J Neurophysiol 71:1128-1138.

Kazaku Y, Akaike N, Komiyama S, Nabekura J (1999) Regulation of intracellular chloride by cotransporters in developing lateral superior olive neurons. J Neurosci 19:2843-2851.

Kirsch J, Betz H (1998) Glycine-receptor activation is required for receptor clustering in spinal neurons. Nature 392:717-720.

Kitzes LM, Semple MN (1985) Single-unit responses in the inferior colliculus: effects of neonatal unilateral cochlear ablation. J Neurophysiol 53:1483-1500.

Kitzes LM, Kageyama GH, Semple MN, Kil J (1995) Development of ectopic projections from the ventral cochlear nucleus to the superior olivary complex induced by neonatal ablation of the contralateral cochlea. J Comp Neurol 353:341-363.

Koch U, Sanes DH (1998) Afferent regulation of glycine receptor distribution in the gerbil LSO. Microsc Res Tech 41:263-269.

Kotak VC, Sanes DH (1995) Synaptically evoked prolonged depolarizations in the developing auditory system. J Neurophysiol 74:1611-1620.

Kotak VC, Sanes DH (1996) Developmental influence of glycinergic transmission: regulation of NMDA receptor-mediated EPSPs. J Neurosci 16:1836-1843.

Kotak VC, Korada S, Schwartz IR, Sanes DH (1998) A developmental shift from GABAergic to glycinergic transmission in the central auditory system. J Neurosci 18:4646-4655.

Kyrozis A, Reichling DB (1995) Perforated patch-recordings with gramicidin avoids artifactual changes in intracellular chloride concentration. J Neurosci Methods 57:27-35.

Laurie DJ, Wisden W, Seeburg PH (1992) The distribution of thirteen $\mathrm{GABA}_{\mathrm{A}}$ receptor subunit mRNAs in the rat brain III. Embryonic and postnatal development. J Neurosci 12:4151-4172.

Le Beau FE, Rees S, Malmierca MS (1996) Contribution of GABA- and glycine-mediated inhibition to the monaural temporal response properties of neurons in the inferior colliculus. J Neurophysiol 75:902-919.

Liu YB, Ye GL, Liu XS, Pasternak JF, Trommer BL (1998) GABA currents in immature dentate gyrus granule cells. J Neurophysiol 80:2255-2267.

Lo Y-J, Rao SC, Sanes DH (1998) Modulation of calcium by inhibitory systems in the developing auditory system. Neuroscience 83:1075-1084.

Malmierca MS, Rees A, Le Beau FE, Bjaalie JG (1995) Laminar organization of frequency-defined local axons within and between the inferior colliculi of the guinea pig. J Comp Neurol 357:124-144.

McAlpine D, Martin RL, Mossop JE, Moore DR (1997) Response properties of neurons in the inferior colliculus of the monaurally deafened ferret to acoustic stimulation of the intact ear. J Neurophysiol 78:767-779.

Merchan MA, Malmierca MS, Bajo VM, Bjaalie JG (1997) The nuclei of the lateral lemniscus. Old view and new perspectives. In: Acoustical signal processing in the central auditory system (Syka, ed), pp 211-226. New York: Plenum.

Milbrandt JC, Albin RL, Caspary DM (1994) Age-related decrease in $\mathrm{GABA}_{\mathrm{B}}$ receptor binding in the Fischer 344 rat inferior colliculus. Neurobiol Aging 15:699-703.

Milbrandt JC, Hunter C, Caspary DM (1997) Alterations of $\mathrm{GABA}_{\mathrm{A}}$ receptor subunit mRNA levels in the aging Fisher 344 rat inferior colliculus. J Comp Neurol 379:455-465.

Moore DR, Kitzes LM (1985) Projections from the cochlear nucleus to the inferior colliculus in normal and neonatally cochlea-ablated gerbils. J Comp Neurol 240:180-195.

Moore DR, Kotak VC, Sanes DH (1998) Commissural and lemniscal synaptic input to the gerbil inferior colliculus. J Neurophysiol 80:2229-2236

Nordeen KW, Killackey HP, Kitzes LM (1983) Ascending auditory projections to the inferior colliculus in the adult gerbil, Meriones unguiculatus. J Comp Neurol 214:131-143.

Oliver DL, Beckius GE, Bishop DC, Kuwada S (1997) Simultaneous anterograde labeling of axonal layers from lateral superior olive and dorsal cochlear nucleus in the inferior colliculus of cat. J Comp Neurol 382:215-229.

Owens DF, Boyce LH, Davies MB, Kriegstein AR (1996) Excitatory GABA responses in embryonic and neonatal cortical slices demonstrated by gramicidin perforated-patch recordings and calcium imaging. J Neurosci 16:6414-6423.

Park TJ, Pollak GD (1993a) GABA shapes sensitivity to interaural intensity disparities in the mustache bat's inferior colliculus: implications for encoding sound location. J Neurosci 13:2050-2059.

Park TJ, Pollak GD (1993b) GABA shapes a topographic organization of response latency in the mustache bat's inferior colliculus. J Neurosci 13:5172-5187.

Park TJ, Pollak GD (1994) Azimuthal receptive fields are shaped by GABAergic inhibition in the inferior colliculus of the mustache bat. J Neurophysiol 72:1080-1102.

Parks TN (1979) Afferent influences on the development of the brain stem auditory nuclei of the chicken: otocyst ablation. J Comp Neurol 183:665-677.

Payne JA, Stevenson TJ, Donaldson LF (1996) Molecular characterization of a putative $\mathrm{K}-\mathrm{Cl}$ cotransporter in rat brain. J Biol Chem 27:16245-16252.

Plotkin MD, Snyder EY, Hebert SC, Delpire E (1997) Expression of the $\mathrm{Na}-\mathrm{K}-2 \mathrm{Cl}$ cotransporter is developmentally regulated in postnatal rat brains: a possible mechanism underlying GABA's excitatory role in immature brain. J Neurobiol 33:781-795.

Potashner SJ, Suneja SK, Benson CG (1997) Regulation of D-aspartate release and uptake in adult brain stem auditory nuclei after unilateral middle ear ossicle removal and cochlear ablation. Exp Neurol 148:222-235.

Poulter MO, Ohannesian L, Larmet Y, Feltz P (1997) Evidence that 
$\mathrm{GABA}_{\mathrm{A}}$ receptor subunit mRNA expression during development is regulated by $\mathrm{GABA}_{\mathrm{A}}$ receptor stimulation. J Neurochem 68:631-639.

Rhee JS, Ebihara S, Akaike N (1994) Gramicidin perforated patchclamp technique reveals glycine-gated outward chloride current in dissociated nucleus solitarii neurons of the rat. J Neurophysiol 72:1103-1108.

Rivera C, Voipio J, Payne JA, Ruusuvuori E, Lahtinen H, Lamsa K, Pirvola U, Saarma M, Kaila K (1999) The $\mathrm{K}^{+} / \mathrm{Cl}^{-}$cotransporter $\mathrm{KCC} 2$ renders GABA hyperpolarizing during neuronal maturation. Nature 397:251-255.

Russell FA, Moore DR (1995) Afferent reorganisation within the superior olivary complex of the gerbil: development and induction by neonatal, unilateral cochlear removal. J Comp Neurol 352:607-625.

Saint Marie RL, Baker RA (1990) Neurotransmitter-specific uptake and retrograde transport of $\left[{ }^{3} \mathrm{H}\right]$ glycine from the inferior colliculus by ipsilateral projections of the superior olivary complex and nuclei of the lateral lemniscus. Brain Res 524:244-253.

Saint Marie RL, Shneiderman A, Stanforth DA (1997) Patterns of gamma-aminobutytic-acid and glycine inmunoreactivities reflect structural and functional differences of the cat lateral lemniscal nuclei. J Comp Neurol 389:264-276.

Saldaña E, Merchan MA (1992) Intrinsic and commissural connections of the rat inferior colliculus. J Comp Neurol 319:417-437.

Sanes DH (1993) The development of synaptic function and integration in the central auditory system. J Neurosci 13:2627-2637.

Sanes DH, Markowitz S, Bernstein J, Wardlow J (1992) The influence of inhibitory afferents on the development of postsynaptic dendritic arbors. J Comp Neurol 321:637-644.

Sanes DH, Malone BJ, Semple MN (1998) Role of synaptic inhibition in processing dynamic binaural level stimuli. J Neurosci 18:794-803.

Seil FJ, Drake-Baumann (1994) Reduced cortical inhibitory synaptogenesis in organotypic cerebellar cultures developing in the absence of neuronal activity. J Comp Neurol 342:366-377.

Shepherd RK, Baxi JH, Hardie NA (1999) Response of inferior colliculus neurons to electrical stimulation of the auditory nerve in neonatally deafened cats. J Neurophysiol 82:1363-1380.

Shneiderman A, Oliver DL, Henkel CK (1988) Connections of the dor- sal nucleus of the lateral lemniscus: an inhibitory parallel pathway in the ascending auditory system? J Comp Neurol 276:188-208.

Shneiderman A, Chase MB, Rockwood JM, Benson CG, Potashner SJ (1993) Evidence for a GABAergic projection from the dorsal nucleus of the lateral lemniscus to the inferior colliculus. J Neurochem 60:72-82.

Smith PH (1992) Anatomy and physiology of multipolar cells in the rat inferior collicular cortex using the in vitro brain slice technique. J Neurosci 12:3700-3715.

Sun D, Murali SG (1998) Stimulation of $\mathrm{Na}^{+}-\mathrm{K}^{+}-2 \mathrm{Cl}^{-}$cotransporter in neuronal cells by excitatory neurotransmitter glutamate. Am J Physiol 275:C772-C779.

Suneja SK, Benson CG, Potashner SJ (1997) Regulation of ${ }^{3} \mathrm{H}$ muscimol binding in central auditory nuclei after cochlear ablation. Assoc Res Otolaryngol Abstr 20:84.

Suneja SK, Potashner SJ, Benson CG (1998a) Plastic changes in glycine and GABA release and uptake in adult brain stem auditory nuclei after unilateral middle ear ossicle removal and cochlear ablation. Exp Neurol $151: 273-288$

Suneja SK, Benson CG, Potashner SJ (1998b) Glycine receptors in adult guinea pig brain stem auditory nuclei: regulation after unilateral cochlear ablation. Exp Neurol 154:473-488.

Vale C, Sanes DH (1999) The effects of bilateral cochlear ablation on synaptic inhibition in the gerbil inferior colliculus. Assoc Res Otolaryngol Abstr 22:534.

Wagner T (1996) Lemniscal input to identified neurons of the central nucleus of mouse inferior colliculus: an intracellular brain slice study. Eur J Neurosci 8:1231-1239.

Wickesberg RE, Whilton D, Oertel D (1994) In vitro modulation of somatic glycine-like immunoreactivity in presumed glycinergic neurons. J Comp Neurol 339:311-327.

Williams JR, Sharp JW, Kumari VG, Wilson M, Payne JA (1999) The neuron-specific $\mathrm{K}-\mathrm{Cl}$ cotransporter, $\mathrm{KCC} 2$.Antibody development and initial characterization of the protein. J Biol Chem 274:12656-12664.

Winer JA, Larue DT, Pollak GD (1995) GABA and glycine in the central auditory system of the mustache bat: structural substrates for inhibitory neuronal organization. J Comp Neurol 355:317-353. 